\title{
ERRATA, VOLUME 9
}

Azriel Lévy, Comparison of subtheories, pp. 942-945.

Page 943 , line 18. Move $S_{2}^{\prime}$ to the end of line 17.

Page 944 , line 7. Move " $\mathrm{B}^{*}-$ " to the end of line 6.

John Jones, Jr., On nonlinear second order differential equations, pp. 586-588.

Page 586, line 19. Delete from (i), "has a" and "lower bound for $x \geqq 0$."

-—, line 20 . Add to (ii), "continuously differentiable for $x \geqq 0$."

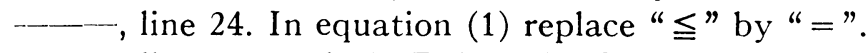

Theorem 1.

, lines 26 and 27. Delete the first sentence in the proof of

- line 29. In equation (2), the expression after the summation should read

$$
\frac{f_{i} y^{2 i}}{2 i}
$$

- line 31 . In equation (3), the expression after the summation should read

$$
\frac{f_{i}^{\prime} y^{2 i}}{2 i}
$$

\section{ERRATA, VOLUME 10}

George Seifert, $A$ note on periodic solutions of second order differential equations without damping, pp. 396-398.

Page 397 , line 25. " $y\left(t_{0}\right)$ " should read “ $\dot{y}\left(t_{0}\right)$ ".

- line 28. The outer set of parentheses in the expression for $m$ should be replaced by absolute value signs.

- _ , line 29. The first " $k$ " should be replaced by " $K$ ". 